\title{
Effects of high temperature and high light on photosystem II activity in leaves of two Bauhinia species
}

\author{
S.B. ZHANG ${ }^{* * *,+}$, Q.L. DENG ${ }^{* * *}$, and Y.J. HAO \\ CAS Key Laboratory of Tropical Forest Ecology, Xishuangbanna Tropical Botanical Garden, Chinese Academy \\ of Sciences, Mengla, 666303 Yunnan, China* \\ Yuanjiang Savanna Ecosystem Research Station, Xishuangbanna Tropical Botanical Garden, Chinese Academy \\ of Sciences, Yuanjiang, 653300 Yunnan, China** \\ School of Geography and Eco-tourism, Southwest Forestry University, 650224 Kunming, Yunnan, China ${ }^{* * *}$ \\ School of Ecology and Environment Conservation, Southwest Forestry University, Kunming, 650224 Yunnan, \\ China $^{\#}$
}

\begin{abstract}
It is, so far, unclear whether lianas and trees differ in photosynthetic thermotolerance and response to high temperature and high light. Here, photosynthetic thermotolerance was compared in the leaves of Bauhinia brachycarpa (tree) and Bauhinia comosa (liana). Moreover, the combined treatments of four temperatures $\left(25,35,40\right.$, and $\left.45^{\circ} \mathrm{C}\right)$ and two light intensities [500 and 2,000 $\mu \mathrm{mol}$ (photon) $\mathrm{m}^{-2} \mathrm{~s}^{-1}$ ] were used to investigate the effects of high temperature and high light on PSII activity. The results showed that $B$. brachycarpa leaves exhibited higher photosynthetic thermotolerance, leaf mass per area, and $\mathrm{Ca}^{2+}$ concentration than those of $B$. comosa. As the temperature and light intensity increased, maximum quantum yield of PSII decreased significantly, particularly with greater declines in B. comosa than that in B. brachycarpa. Our results suggested that PSII was more sensitive to high temperature and high light in liana species $B$. comosa than in the congener tree species B. brachycarpa.
\end{abstract}

Additional key words: global warming; heat stress; photoinhibition; photoprotection.

\section{Introduction}

Lianas, an important component of tropical forests, strongly compete with co-occurring trees, which in turn can alter plant community composition and affect forest regeneration (Schnitzer and Bongers 2002, Schnitzer 2018). Both the richness and biomass of lianas increased in many tropical and secondary forests (Wright et al. 2004a, Schnitzer and Bongers 2011). High liana abundance has been indicated to suppress tree regeneration, increase tree mortality (Schnitzer and Bongers 2002, Ingwell et al. 2010, De Deurwaerder et al. 2018), and even reduce carbon storage in tropical forests (Durán and SánchezAzofeifa 2015).

It has been proposed that lianas had stronger stomatal regulation, more efficient hydraulic conductivity (Zhang et al. 2016, Chen et al. 2017), better seasonal adjustment in leaf turgor loss point (Maréchaux et al. 2017), and greater external mechanical stability of canopy terminal branches (Zhang et al. 2019), compared to the co-occurring trees. More recently, lianas have been suggested to have a seasonal growth advantage over co-occurring trees (Schnitzer and van der Heijden 2019). Together, these results provided potential physiological explanations for the faster growth strategy of lianas over trees.

With changes in the global climate, plant species may be significantly affected by global warming (Corlett and Westcott 2013). High temperature (HT) stress brings plant species closer to their physiological limits, especially in tropical forests (Doughty and Goulden 2008). The leaf surfaces exposed to direct sunlight occasionally reach the temperature of $7.6^{\circ} \mathrm{C}$ higher than that of the ambient air (Noffsinger 1961). However, it remains unclear how the photosynthetic performance of both lianas and trees is

Received 9 July 2019, accepted 16 September 2019.

${ }^{+}$Corresponding author; phone: +866918713046 , e-mail: zhangshubin@xtbg.ac.cn

Abbreviations: $\mathrm{F}_{0}$ - minimum dark-adapted fluorescence; $\mathrm{F}_{\mathrm{m}}-$ maximum dark-adapted fluorescence; $\mathrm{F}_{\mathrm{v}} / \mathrm{F}_{\mathrm{m}}-$ maximum quantum yield of PSII; HL - high light; HT - high temperature; LMA - leaf mass per area; LSP - light-saturation point; NPQ - nonphotochemical quenching; $P_{\mathrm{N}}-$ net photosynthetic rate; $P_{\mathrm{N} \max }-$ light-saturated net photosynthetic rate; PT - photosynthetic thermotolerance; $\mathrm{T}_{\mathrm{c}}$ - critical high temperature threshold for the change from inactivation to irreversible destruction of PSII; $\mathrm{T}_{\text {cond }}-$ threshold temperature of the leakage of ions from cells.

Acknowledgements: This study was funded by the National Natural Science Foundation of China (31600479, 41861144016), the CAS Scholarship for visiting research (2018-24), and the CAS 'Light of West China' Program to Shubin Zhang. We are very grateful to the Yuanjiang Savanna Ecosystem Research Station, Xishuangbanna Tropical Botanical Garden, Chinese Academy of Sciences, for providing the meteorological data and LI-6400XT portable photosynthesis system. We also thank Mr. Wanyou Dao for sampling assistance and Dr. Hua Lin for the measurements of photosynthetic thermotolerance. 
affected by global warming. HT usually combines with high light (HL) in the natural environment. PSII is a stresssensitive component of the photosynthetic apparatus and is photoinhibited as a result of $\mathrm{HT}$ and $\mathrm{HL}(\mathrm{Hu}$ et al. 2009). The heat-induced inactivation of PSII includes reversible and irreversible inactivation. The inactivation of PSII as a result of moderate HT can be reversed by transfer of cells to $25^{\circ} \mathrm{C}$. However, the inactivation by heat stress higher than $45^{\circ} \mathrm{C}$ was irreversible in soybean (Glycine max) (Nishiyama et al. 2006a). Previous studies have suggested that moderate heat stress may inhibit the repair of photodamaged PSII (Takahashi et al. 2004), and strong heat stress has been shown to deactivate the oxygen-evolving complex (OEC) in PSII (Nash et al. 1985, Murata et al. 2007). Photosynthetic thermotolerance (PT) is defined as the change in excitation capacity of PSII under HT, and may be used to evaluate PSII performance in leaves under heat stress (Knight and Ackerly 2003, Zhang et al. 2012). There is a great variation in PT across species even grown in a common environment (Knight and Ackerly 2003), and it has been shown that the interspecies variation in PT was related to leaf lifespan, leaf mass per area (LMA), and leaf $\mathrm{Ca}^{2+}$ concentration (Zhang et al. 2012). A high LMA may limit the water transport efficiency, but promote heat resistance (Zhang et al. 2012, Sastry et al. 2018). PT has also exhibited high plasticity to seasonal changes and temperature treatments in the same species (Weng and Lai 2005). High light not only damages PSII activity directly, but also inhibits the repair of PSII via production of reactive oxygen species (ROS) inhibiting expression of the D1 protein at the translation step (Allakhverdiev et al. 2005, Nishiyama et al. 2005, 2006b, 2011; Takahashi and Murata 2008).

Lianas and trees differ strikingly in life growth forms and water use strategies (Chen et al. 2015, Zhang et al. 2016). Our previous study also suggested that lianas have higher stem and leaf-specific hydraulic conductivity, and photorespiration, than that of co-occurring trees under environmental stress-free conditions (Zhang et al. 2016). However, little is known about the different responses of PSII to HT and HL for lianas. Maximum quantum yield of PSII $\left(\mathrm{F}_{\mathrm{v}} / \mathrm{F}_{\mathrm{m}}\right)$ is a reliable diagnostic indicator of photosynthetic function in response to environmental stresses, such as light, temperature, drought, and salt (Murata et al. 2007, Takahashi and Murata 2008). In the present study, we compared photosynthetic thermotolerance and the response of $\mathrm{F}_{\mathrm{v}} / \mathrm{F}_{\mathrm{m}}$ to $\mathrm{HT}$ and $\mathrm{HL}$ in the leaves of Bauhinia brachycarpa (tree) and Bauhinia comosa (liana). We sought answers to the following three questions: (1) Does PT differ between two Bauhinia species with contrasting growth forms? (2) Does PSII activity in response to HT and HL differ between the two species? (3) Are the differences in PT and response of PSII activity to HT and HL associated with specific leaf traits (LMA and leaf element content)?

\section{Materials and methods}

The study site was located in Yuanjiang Savanna Ecosystem Research Station $\left(23^{\circ} 27^{\prime} \mathrm{N}, 102^{\circ} 10^{\prime} \mathrm{E}, 481 \mathrm{~m}\right.$ a.s.l.), in Yuanjiang County, Yunnan Province, China. Based on the meteorological record of 2012-2017, mean annual air temperature was $23.7^{\circ} \mathrm{C}$, and mean annual precipitation was $732.8 \mathrm{~mm}$. The midday air temperature can reach over $40^{\circ} \mathrm{C}$ in summer, with an extreme air temperature of $43.7^{\circ} \mathrm{C}$ at midday. The soil type was ferralic cambisol. The typical vegetation in this site was valley-type savanna with a mixture of co-occurring trees and lianas (Jin and $\mathrm{Ou}$ 2000, Zhang et al. 2016).

Plants: Five individuals of $B$. brachycarpa and B. comosa were selected from a long-term monitoring plot $(100 \times$ $100 \mathrm{~m})$ for savanna ecosystem $\left(23^{\circ} 28^{\prime} 25^{\prime \prime} \mathrm{N}, 102^{\circ} 10^{\prime} 38^{\prime \prime} \mathrm{E}\right.$, $565 \mathrm{~m}$ a.s.1.). When plants were growing under optimal conditions in August 2018, fully expanded and sunexposed leaves from five individuals per species were used to assess photosynthesis and chlorophyll (Chl) fluorescence parameters.

Gas exchange: Photosynthetic light responses were measured between 9:00-11:00 $\mathrm{h}$ on sunny days using a LI-6400XT portable photosynthesis system ( $\mathrm{Li}$-Cor, Lincoln, NE, USA). Leaf temperature was set at $30^{\circ} \mathrm{C}$ and $\mathrm{CO}_{2}$ concentration in the incoming air was $400 \mu \mathrm{mol}\left(\mathrm{CO}_{2}\right)$ $\mathrm{mol}^{-1}$ controlled by a 6400-01 $\mathrm{CO}_{2}$ injector system ( $\mathrm{Li}$-Cor, Lincoln, NE, USA). Photosynthetic light responses were generated from measurements obtained at 2,000; 1,$500 ; 1,000 ; 500,200,100,50,20$, and $0 \mu \mathrm{mol}$ (photon) $\mathrm{m}^{-2} \mathrm{~s}^{-1}$. Steady-state photosynthesis was maintained for at least 3 min under each PPFD. The light-saturated net photosynthetic rate $\left(P_{\mathrm{Nmax}}\right)$ and light-saturation point (LSP) were fitted according to a nonrectangular hyperbola.

Photosynthetic thermotolerance was determined using PlanTherm PT100 (Photon Systems Instruments, Czech Republic). Leaf segments taken from the middle of the sampled leaves were submerged in water bath with distilled water. The water temperature was gradually heated from $25^{\circ} \mathrm{C}$ up to $70^{\circ} \mathrm{C}$ (increase of $1-3^{\circ} \mathrm{C} \mathrm{min}^{-1}$ ). The conductivity and $\mathrm{Chl}$ fluorescence transients were continuously monitored with changes in the water temperature. The fluorescence $\left(\mathrm{F}_{\mathrm{t}}\right)$ and temperature curves were used to determine the critical high temperature threshold $\left(\mathrm{T}_{\mathrm{c}}\right)$, in which the change from inactivation to irreversible destruction of PSII occurred. Further, conductivity and temperature curves were used to determine the threshold temperature of the leakage of ions from cells $\left(\mathrm{T}_{\text {cond }}\right)$.

Leaf traits: More than 30 mature leaves from five individuals per species were sampled and the leaf area was determined with $L i$-3000A leaf area meter (Li-Cor, Nebraska, USA). The leaf dry mass was measured after oven-drying at $70^{\circ} \mathrm{C}$ for $48 \mathrm{~h}$. The leaf mass per area (LMA) was calculated as the leaf dry mass divided by the total leaf area. The leaf samples were grinded to measure the leaf $\mathrm{Ca}^{2+}$ concentration $\left[\mathrm{mg} \mathrm{g}^{-1}(\mathrm{DM})\right]$. After the leaf samples were digested by $\mathrm{HNO}_{3}-\mathrm{HClO}_{4}$, leaf $\mathrm{Ca}^{2+}$ concentration was determined using an inductively coupled plasma atomic-emission spectrometer (iCAP6300, Thermo Fisher Scientific, USA). 
HT and HL treatments: Detached leaves were exposed to the combined treatments of four temperatures $(25,35,40$, and $45^{\circ} \mathrm{C}$ ) supplied by a water bath (Jintan Science Analysis Instrument Co., Ltd., China), and two light intensities [500 and 2,000 $\mu \mathrm{mol}$ (photon) $\mathrm{m}^{-2} \mathrm{~s}^{-1}$ ] continuously provided by an LED-light source for $2 \mathrm{~h}$. Five replicates of each combined treatment were carried out. After each treatment, detached leaves were acclimated to darkness for $30 \mathrm{~min}$. The $\mathrm{Chl}$ fluorescence parameters were evaluated using a PAM-2100 fluorometer (Heinz Walz, Effeltrich, Germany). Minimal dark-adapted fluorescence $\left(\mathrm{F}_{0}\right)$ was determined for the dark-acclimated leaves. The intensity for the measurements of $\mathrm{F}_{0}$ was $0.1 \mu \mathrm{mol}$ (photon) $\mathrm{m}^{-2} \mathrm{~s}^{-1}$. This low intensity of the exciting light allows the detection of $\mathrm{F}_{0}$ (Ilík et al. 2018). Then, maximum dark-adapted fluorescence $\left(\mathrm{F}_{\mathrm{m}}\right)$ was determined after a 0.8 -s saturating pulse at 5,000 $\mu \mathrm{mol}$ (photon) $\mathrm{m}^{-2} \mathrm{~s}^{-1} . \mathrm{F}_{\mathrm{v}} / \mathrm{F}_{\mathrm{m}}$ was calculated as $\left(\mathrm{F}_{\mathrm{m}}-\mathrm{F}_{0}\right) / \mathrm{F}_{\mathrm{m}}$.

Statistical analysis: The values of leaf photosynthetic and functional traits were presented as the means $\pm \mathrm{SE}$. Statistically significant differences in photosynthetic and leaf trait parameters between two species were performed by independent-sample $t$-test. Two-way analysis of variance $(A N O V A)$ was performed to assess the effects of temperature and light on $\mathrm{F}_{\mathrm{v}} / \mathrm{F}_{\mathrm{m}}$. Significance level was set at $P<0.05$. Statistical analysis was performed using SPSS 17.0 software (SPSS Inc., Chicago, IL, USA). The figures were plotted with Sigmaplot version 12.0 software.

\section{Results}

Comparison of light-response curves: There was no significant difference in $P_{\mathrm{N}}$ between the two species under low PPFDs of 20-200 $\mu \mathrm{mol}$ (photon) $\mathrm{m}^{-2} \mathrm{~s}^{-1}$. However, B. brachycarpa exhibited higher values of $P_{\mathrm{N}}$ than that of $B$. comosa under the PPFDs, which were greater than $500 \mu \mathrm{mol}$ (photon) $\mathrm{m}^{-2} \mathrm{~s}^{-1}$ (Fig. 1). The $P_{\mathrm{Nmax}}$ was significantly higher in $B$. brachycarpa $\left[20.2 \mu \mathrm{mol}\left(\mathrm{CO}_{2}\right) \mathrm{m}^{-2} \mathrm{~s}^{-1}\right]$ than that in $B$. comosa $\left[16.2 \mu \mathrm{mol}\left(\mathrm{CO}_{2}\right) \mathrm{m}^{-2} \mathrm{~s}^{-1}\right]$ (Fig. $2 A$ ). Light-saturation point (LSP) values were 1,137.6 and $893.6 \mu \mathrm{mol}$ (photon) $\mathrm{m}^{-2} \mathrm{~s}^{-1}$ for $B$. brachycarpa and B. comosa, respectively. Both Bauhinia species are lightdemanding plants, however, the tree species B. brachycarpa had a significantly higher LSP than the congener liana species B. comosa (Fig. 2B).

Comparison of PT: $T_{c}$ was used to indicate the inactivation to irreversible destruction of PSII reaction centers (Bilger et al. 1984, Zhang et al. 2012). According to the parameters of $\mathrm{PT}, \mathrm{T}_{\mathrm{c}}$ was significantly higher in B. brachycarpa $\left(47.2 \pm 0.3^{\circ} \mathrm{C}\right)$ than that in $B$. comosa $\left(45.8 \pm 0.3^{\circ} \mathrm{C}\right)($ Fig. $2 C) . \mathrm{T}_{\text {cond }}$ was used to indicate the cell membrane thermostability under heat treatment (Ilík et al. 2018). The $\mathrm{T}_{\text {cond }}$ were $59.6 \pm 0.5^{\circ} \mathrm{C}$ and $59.0 \pm 0.3^{\circ} \mathrm{C}$ for $B$. brachycarpa and B. comosa, respectively, and no significant difference was found for the $\mathrm{T}_{\text {cond }}$ values between the two Bauhinia species (Fig. 2D).

LMA and leaf $\mathrm{Ca}^{2+}$ concentration: $B$. brachycarpa had

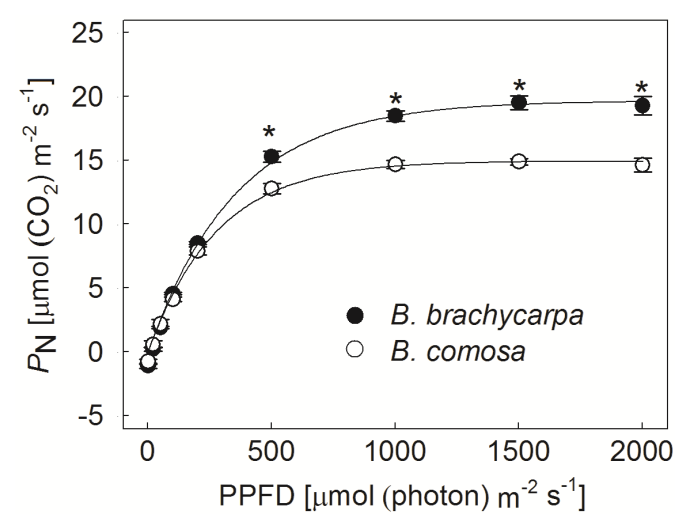

Fig. 1. Comparisons of light-response curves in the leaves of Bauhinia brachycarpa and B. comosa. Asterisks indicate significant differences of $P_{\mathrm{N}}$ between $B$. brachycarpa and $B$. comosa $(P<0.05)$. The results were displayed as means $\pm \mathrm{SE}$ $(n=5)$.

significantly greater LMA and leaf $\mathrm{Ca}^{2+}$ concentration than that of $B$. comosa (Fig. $2 E, F$ ). This result suggested that $B$. comosa leaves may be more vulnerable to irreversible thermal damage than those of B. brachycarpa.

The effects of $\mathbf{H T}$ and $\mathbf{H L}$ on $\mathbf{F}_{\mathrm{v}} / \mathbf{F}_{\mathbf{m}}$ : The $\mathrm{F}_{\mathrm{v}} / \mathrm{F}_{\mathrm{m}}$ was significantly affected by light intensity and temperature in both Bauhinia species (Table 1, two-way ANOVA). Under both 500 and 2,000 $\mu \mathrm{mol}$ (photon) $\mathrm{m}^{-2} \mathrm{~s}^{-1}, \mathrm{~F}_{\mathrm{v}} / \mathrm{F}_{\mathrm{m}}$ decreased as the treatment temperature increased (Fig. 3). At moderate light and high temperatures $\left(40\right.$ and $\left.45^{\circ} \mathrm{C}\right)$, the $\mathrm{F}_{\mathrm{v}} / \mathrm{F}_{\mathrm{m}}$ values were significantly higher in $B$. brachycarpa than that in $B$. comosa (Fig. 3A). At the high light, the $\mathrm{F}_{\mathrm{v}} / \mathrm{F}_{\mathrm{m}}$ of $B$. brachycarpa was significantly higher at all temperatures (Fig. 3B).

\section{Discussion}

Environmental stresses, such as salt, heat, and drought stress, enhance photoinhibition of PSII (Murata et al. 2007, Nishiyama et al. 2005, 2006a,b; Takahashi and Murata 2008). The extent of photoinhibition is determined by the balance between photodamage to PSII and subsequent repair (Murata et al. 2007, Takahashi and Murata 2008). In this study, $F_{v} / F_{m}$ values varied inversely with elevated temperature and light intensity for both Bauhinia species, with a greater decrease in $\mathrm{F}_{\mathrm{v}} / \mathrm{F}_{\mathrm{m}}$ values in B. comosa (Fig. 3). This result indicated that PSII activity was more sensitive to HT and HL in B. comosa than in B. brachycarpa. $B$. brachycarpa had higher LMA, leaf $\mathrm{Ca}^{2+}$ concentration, and $\mathrm{T}_{\mathrm{c}}$ than that of $B$. comosa (Fig. 2). Considering the close association between photosynthetic thermotolerance and leaf traits (Knight and Ackerly 2003, Zhang et al. 2012, Sastry et al. 2018), the higher $\mathrm{T}_{\mathrm{c}}$ of B. brachycarpa may be related to the higher values of LMA and leaf $\mathrm{Ca}^{2+}$ concentration.

Previous studies have indicated that a higher LMA is linked to a longer leaf lifespan and a higher carbon-cost of deploying a new leaf (Wright et al. 2004b, Onoda et al. 2011). The longer-living leaves may experience a higher 


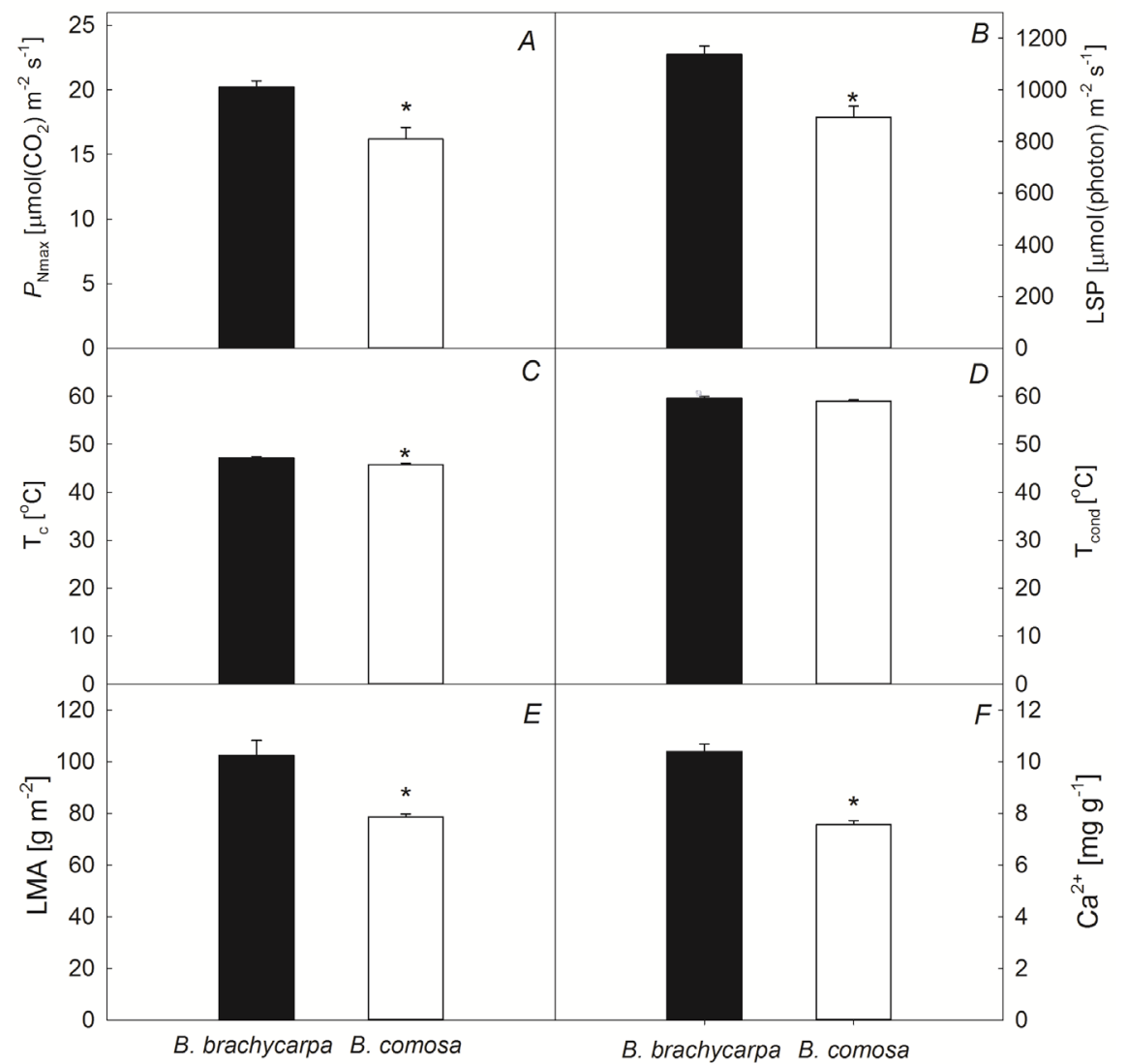

Fig. 2. Comparisons of photosynthetic and nutrient parameters in the leaves of Bauhinia brachycarpa and B. comosa. Light-saturated net photosynthetic rate $\left(P_{\text {Nmax }}\right)(A)$, light-saturation point (LSP) $(B)$, the critical high temperature threshold where the change from inactivation to irreversible destruction of PSII occurs $\left(T_{c}\right)(C)$, the threshold temperature of the leakage of ions from cells $\left(\mathrm{T}_{\text {cond }}\right)(D)$, leaf mass per area (LMA) $(E)$, and leaf $\mathrm{Ca}^{2+}$ concentration $(\mathrm{Ca})(F)$. Asterisks indicate significant differences between B. brachycarpa and B. comosa $(P<0.05)$. The results were displayed as means $\pm \mathrm{SE}$ $(n=5)$.

Table 1. Two-way ANOVA results of the effects of high light and high temperature on maximum quantum yield of PSII $\left(\mathrm{F}_{\mathrm{v}} / \mathrm{F}_{\mathrm{m}}\right)$ in Bauhinia brachycarpa and B. comosa leaves.

\begin{tabular}{llllllr}
\hline Species & \multicolumn{2}{l}{ Temperature } & \multicolumn{2}{l}{ Light } & \multicolumn{3}{c}{ Temperature $\times$ Light } \\
& $F$ & Sig. & $F$ & Sig. & $F$ & Sig. \\
\hline Bauhinia brachycarpa & 30.76 & $<0.001$ & 264.04 & $<0.001$ & 7.89 & $<0.001$ \\
Bauhinia comosa & 67.89 & $<0.001$ & 295.28 & $<0.001$ & 0.58 & 0.633 \\
\hline
\end{tabular}

risk of heat stress. It has been shown that the PT of some species is positively correlated to the leaf lifespan (Zhang et al. 2012). The higher LMA in B. brachycarpa indicates slower turnover and higher need for heat resistance compared to B. comosa. In addition, Knight and Ackerly (2003) reported that species with higher LMA have high expression levels of the heat shock proteins (HSPs), which are involved in maintaining of protein structural stability, alleviate cell membrane damage, and reduce protein misfolding (Swindell et al. 2007, Qi et al. 2019). Moreover, $\mathrm{Ca}^{2+}$ has been suggested to play an important role in maintaining the structural rigidity of the cell wall and cell membrane permeability during heat stress (Hepler 2005). Heat shock-triggered $\mathrm{Ca}^{2+}$ mobilization may be a universal response under heat stress to improve the thermotolerance in plant leaves (Wu and Jinn 2010). The higher $\mathrm{Ca}^{2+}$ concentration may promote the thermostability of OEC, and, owing to lesser accumulation of ROS, partly maintain photochemical efficiency of PSII (Tan et al. 2011). Thus, the higher LMA and leaf $\mathrm{Ca}^{2+}$ concentration may be related to higher thermotolerance in B. brachycarpa.

In this study, both Bauhinia species showed a significant decline in PSII activity under the 40 and $45^{\circ} \mathrm{C}$ treatments in moderate light $\left[500 \mu \mathrm{mol}\left(\right.\right.$ photon) $\left.\mathrm{m}^{-2} \mathrm{~s}^{-1}\right]$ (Fig. 3A). This is in agreement with the finding that the heat stress may lead to an imbalance in the electron flow from OEC toward the acceptor side of PSII in the direction of PSI reaction center (De Ronde et al. 2004). After exposure to a HL treatment of 2,000 $\mu \mathrm{mol}$ (photon) $\mathrm{m}^{-2} \mathrm{~s}^{-1}$, the decline in $\mathrm{F}_{\mathrm{v}} / \mathrm{F}_{\mathrm{m}}$ was further aggravated for both Bauhinia species than that in moderate light $\left[500 \mu \mathrm{mol}\left(\right.\right.$ photon) $\left.\mathrm{m}^{-2} \mathrm{~s}^{-1}\right]$, even under an optimal growth temperature $\left(25^{\circ} \mathrm{C}\right)$ (Fig. $3 B$ ). Due to the effect of a photoinhibitory light intensity, the increase of temperature above $25^{\circ} \mathrm{C}$ led to further decrease of $\mathrm{F}_{\mathrm{v}} / \mathrm{F}_{\mathrm{m}}$ (Fig. $3 B$ ) as a result of the combined HL and HT stress (Zhang et al. 2012, Dongsansuk et al. 2013, Takahashi and Murata 2008, Nishiyama et al. 2004, 2006b, 2011). 


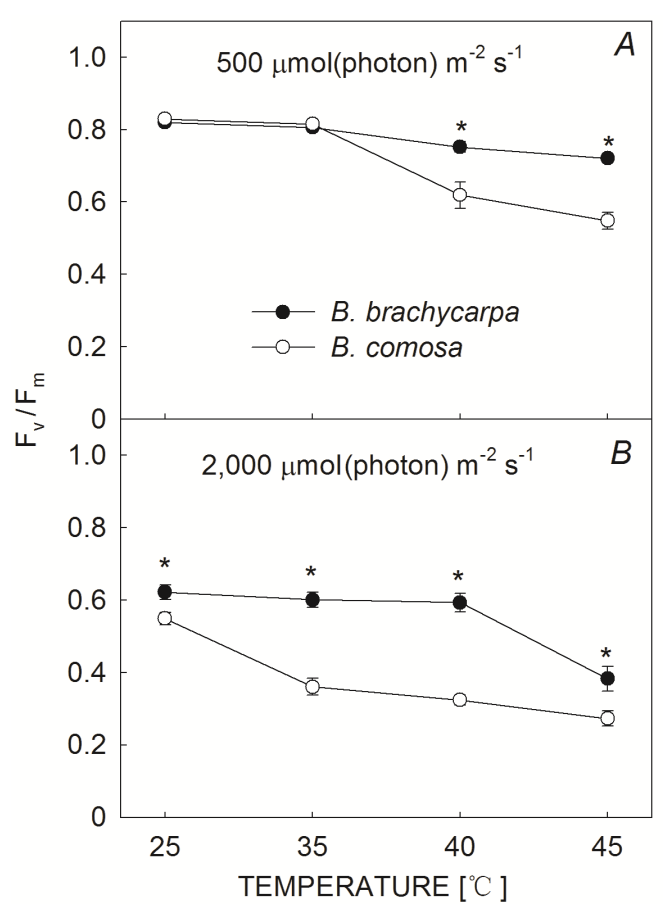

Fig. 3. Changes in the maximum quantum yield of PSII $\left(\mathrm{F}_{\mathrm{v}} / \mathrm{F}_{\mathrm{m}}\right)$ during exposure to high light and high temperature in detached leaves of Bauhinia brachycarpa and B. comosa. Asterisks indicate significant differences of $\mathrm{F}_{\mathrm{v}} / \mathrm{F}_{\mathrm{m}}$ between $B$. brachycarpa and $B$. comosa $(P<0.05)$. The results were displayed as means $\pm \mathrm{SE}$ $(n=5)$.

Lianas have been reported to have a higher hydraulic efficiency and a faster growth strategy than co-occurring trees (Zhang et al. 2016, Chen et al. 2017). Moreover, lianas allocated more excited light energy used for photorespiration to promote photoprotection compared to trees under current climate conditions (Zhang et al. 2016). In this study, $B$. comosa showed a greater decline in PSII activity under HT and HL than that of B. brachycarpa (Fig. 3). More sensitive PSII in liana species may decrease the photosynthetic carbon gain and growth performance. The findings of this study suggest that the growth advantage of lianas over trees might be weakened or even disappear due to global warming, which may alter species composition and forest regeneration.

Conclusion: The leaves of the tree species B. brachycarpa exhibited higher PT than those of the congener liana $B$. comosa. This may be related to the higher LMA and leaf $\mathrm{Ca}^{2+}$ concentration in B. brachycarpa. Further, PSII was more sensitive to the combined HT and HL stress in the liana than in the tree. Despite the lianas seem to have a seasonal growth advantage over co-occurring trees (Schnitzer and Bongers 2011, Schnitzer and van der Heijden 2019), the higher sensitivity of the photosynthetic apparatus may negatively affect photosynthetic carbon gain and subsequently the growth performance and fitness (McAlpine et al. 2008, Imbamba and Tieszen 2010, Slot and Winter 2017), under the expected global warming. In order to predict the long-term responses of co-occurring lianas and trees to the climate change, further studies are required to elucidate the integrated effect of the extreme temperatures, drought, and high light on the hydraulic and photosynthetic processes.

\section{References}

Allakhverdiev S.I., Tsvetkova N., Mohanty P. et al.: Irreversible photoinhibition of photosystem II is caused by exposure of Synechocystis cells to strong light for a prolonged period. BBA-Bioenergetics 1708: 342-351, 2005.

Bilger H.W., Schreiber U., Lange O.L.: Determination of leaf heat resistance: comparative investigation of chlorophyll fluorescence changes and tissue necrosis methods. Oecologia 63: 256-262, 1984.

Chen Y.J., Cao K.F., Schnitzer S.A. et al.: Water-use advantage for lianas over trees in tropical seasonal forests. - New Phytol. 205: 128-136, 2015.

Chen Y.J., Schnitzer S.A., Zhang Y.J. et al.: Physiological regulation and efficient xylem water transport regulate diurnal water and carbon balances of tropical lianas. - Funct. Ecol. 31: 306-317, 2017.

Corlett R.T., Westcott D.A.: Will plant movements keep up with climate change? - Trends Ecol. Evol. 28: 482-488, 2013.

De Deurwaerder H., Hervé-Fernández P., Stahl C. et al.: Liana and tree below-ground water competition - evidence for water resource partitioning during the dry season. - Tree Physiol. 38: 1071-1083, 2018.

De Ronde J.A., Cress W.A., Krüger G.H.J. et al.: Photosynthetic response of transgenic soybean plants, containing an Arabidopsis P5CR gene, during heat and drought stress. J. Plant Physiol. 161: 1211-1224, 2004.

Dongsansuk A., Lütz C., Neuner G.: Effects of temperature and irradiance on quantum yield of PSII photochemistry and xanthophyll cycle in a tropical and a temperate species. Photosynthetica 51: 13-21, 2013.

Doughty C.E., Goulden M.L.: Are tropical forests near a high temperature threshold? - J. Geophys. Res.-Biogeo. 113: G00B07, 2008.

Durán S.M., Sánchez-Azofeifa G.A.: Liana effects on carbon storage and uptake in mature and secondary tropical forests. In: Parthasarathy N. (ed.): Biodiversity of Lianas. Vol. 5. Pp. 43-55. Springer, Cham 2015.

Hepler P.K.: Calcium: A central regulator of plant growth and development. - Plant Cell 17: 2142-2155, 2005.

$\mathrm{Hu}$ M.J., Guo Y.P., Shen Y.G. et al.: Midday depression of photosynthesis and effects of mist spray in citrus. - Ann. Appl. Biol. 154: 143-155, 2009.

Ilík P., Špundová M., Šicner M. et al.: Estimating heat tolerance of plants by ion leakage: A new method based on gradual heating. - New Phytol. 218: 1278-1287, 2018.

Imbamba S.K., Tieszen L.T.: Influence of light and temperature on photosynthesis and transpiration in some $\mathrm{C}_{3}$ and $\mathrm{C}_{4}$ vegetable plants from Kenya. - Physiol. Plantarum 39: 311$316,2010$.

Ingwell L.L., Wright S.J., Becklund K.K. et al.: The impact of lianas on 10 years of tree growth and mortality on Barro Colorado Island, Panama. - J. Ecol. 98: 879-887, 2010.

Jin Z.Z., Ou X.K.: [Vegetations in the hot and dry valleys along the Yuanjiang, Nujiang, Jinshajiang, and Lanchangjiang Rivers.] Pp. 271-273. Yunnan University Press, Kunming 2000. [In Chinese]

Knight C.A., Ackerly D.D.: Evolution and plasticity of photosynthetic thermal tolerance, specific leaf area and leaf size: congeneric species from desert and coastal environments. - 
New Phytol. 160: 337-347, 2003.

Maréchaux I., Bartlett M.K., Iribar A. et al.: Stronger seasonal adjustment in leaf turgor loss point in lianas than trees in an Amazonian forest. - Biol. Lett.-UK 13: 20160819, 2017.

McAlpine K.G., Jesson L.K., Kubien D.S.: Photosynthesis and water-use efficiency: A comparison between invasive (exotic) and non-invasive (native) species. - Austral. Ecol. 33: 10-19, 2008.

Murata N., Takahashi S., Nishiyama Y., Allakhverdiev S.I.: Photoinhibition of photosystem II under environmental stress.BBA-Bioenergetics 1767: 414-421, 2007.

Nash D., Miyao M., Murata N.: Heat inactivation of oxygen evolution in Photosystem II particles and its acceleration by chloride depletion and exogenous manganese. BBA-Bioenergetics 807: 127-133, 1985.

Nishiyama Y., Allakhverdiev S.I., Murata N.: Inhibition of the repair of Photosystem II by oxidative stress in cyanobacteria. Photosynth. Res. 84: 1-7, 2005.

Nishiyama Y., Allakhverdiev S.I., Murata N.: A new paradigm for the action of reactive oxygen species in the photoinhibition of photosystem II. - BBA-Bioenergetics 1757: 742-749, $2006 \mathrm{~b}$.

Nishiyama Y., Allakhverdiev S.I., Murata N.: Protein synthesis is the primary target of reactive oxygen species in the photoinhibition of photosystem II. - Physiol. Plantarum 142: 35-46, 2011.

Nishiyama Y., Allakhverdiev S.I., Yamamoto H. et al.: Singlet oxygen inhibits the repair of photosystem II by suppressing the translation elongation of the D1 protein in Synechocystis sp. PCC 6803. - Biochemistry 43: 11321-11330, 2004.

Nishiyama Y., Takechi K., Nanjo Y. et al.: Acclimation of photosystem II to high temperature in a suspension culture of soybean (Glycine max) cells requires proteins that are associated with the thylakoid membrane.-Photosynth. Res.90: 223-232, 2006a.

Noffsinger T.L.: Leaf and air temperature under Hawaii conditions. - Pac. Sci. 15: 304-306, 1961.

Onoda Y., Westoby M., Adler P.B. et al.: Global patterns of leaf mechanical properties. - Ecol. Lett. 14: 301-312, 2011.

Qi C.D., Lin X.P., Li S.T. et al.: SoHSC70 positively regulates thermotolerance by alleviating cell membrane damage, reducing ROS accumulation, and improving activities of antioxidant enzymes. - Plant Sci. 283: 385-395, 2019.

Sastry A., Guha A., Barua D.: Leaf thermotolerance in dry tropical forest tree species: relationships with leaf traits and effects of drought. - AoB Plants 10: plx070, 2018.

Schnitzer S.A.: Testing ecological theory with lianas. - New Phytol. 220: 366-380, 2018.

Schnitzer S.A., Bongers F.: The ecology of lianas and their role in forests. - Trends Ecol. Evol. 17: 223-230, 2002.
Schnitzer S.A., Bongers F.: Increasing liana abundance and biomass in tropical forests: emerging patterns and putative mechanisms. - Ecol. Lett. 14: 397-406, 2011.

Schnitzer S.A., van der Heijden G.M.F.: Lianas have a seasonal growth advantage over co-occurring trees. - Ecology 100: e02655, 2019.

Slot M., Winter K.: In situ temperature response of photosynthesis of 42 tree and liana species in the canopy of two Panamanian lowland tropical forests with contrasting rainfall regimes. New Phytol. 214: 1103-1117, 2017.

Swindell W.R., Huebner M., Weber A.P.: Transcriptional profiling of Arabidopsis heat shock proteins and transcription factors reveals extensive overlap between heat and non-heat stress response pathways. - BMC Genomics 8: 15, 2007.

Takahashi S., Murata N.: How do environmental stresses accelerate photoinhibition? - Trends Plant Sci. 13: 178-182, 2008.

Takahashi S., Nakamura T., Sakamizu M. et al.: Repair machinery of symbiotic photosynthesis as the primary target of heat stress for reef-building corals. - Plant Cell Physiol. 45: 251-255, 2004.

Tan W., Meng Q.W., Brestič M. et al.: Photosynthesis is improved by exogenous calcium in heat-stressed tobacco plants. J. Plant Physiol. 168: 2063-2071, 2011.

Weng J.H., Lai M.F.: Estimating heat tolerance among plant species by two chlorophyll fluorescence parameters. Photosynthetica 43: 439-444, 2005.

Wright I.J., Reich P.B., Mark W. et al.: The worldwide leaf economics spectrum. - Nature 428: 821-827, 2004b.

Wright S.J., Calderón O., Hernandéz A., Paton S.: Are lianas increasing in importance in tropical forests? A 17-year record from Panama. - Ecology 85: 484-489, 2004a.

Wu H.C., Jinn T.L.: Heat shock-triggered $\mathrm{Ca}^{2+}$ mobilization accompanied by pectin methylesterase activity and cytosolic $\mathrm{Ca}^{2+}$ oscillation are crucial for plant thermotolerance. - Plant Signal. Behav. 5: 1252-1256, 2010.

Zhang J.L., Poorter L., Hao G.Y., Cao K.F.: Photosynthetic thermotolerance of woody savanna species in China is correlated with leaf life span. - Ann. Bot.-London 110: 10271033, 2012.

Zhang L., Chen Y., Ma K. et al.: Fully exposed canopy tree and liana branches in a tropical forest differ in mechanic traits but are similar in hydraulic traits. - Tree Physiol.: https://doi. org/10.1093/treephys/tpz070, 2019. (Ahead of print)

Zhang S.B., Zhang J.L., Cao K.F.: Differences in the photosynthetic efficiency and photorespiration of co-occurring Euphorbiaceae liana and tree in a Chinese savanna. Photosynthetica 54: 438-445, 2016.

(C) The authors. This is an open access article distributed under the terms of the Creative Commons BY-NC-ND Licence. 